\title{
Scardovia wiggsiae sp. nov., isolated from the human oral cavity and clinical material, and emended descriptions of the genus Scardovia and Scardovia inopinata
}

Correspondence William G. Wade william.wade@kcl.ac.uk

\author{
Julia Downes, ${ }^{1}$ Maria Mantzourani, ${ }^{1}$ David Beighton, ${ }^{1}$ Samuel Hooper, ${ }^{2}$ \\ Melanie J. Wilson, ${ }^{2}$ Ainsley Nicholson ${ }^{3}$ and William G. Wade ${ }^{1}$ \\ 'King's College London Dental Institute at Guy's, King's College and St Thomas' Hospitals, Infection \\ Research Group, London, SE1 9RT, UK \\ ${ }^{2}$ Cardiff University School of Dentistry, Heath Park, Cardiff, CF14 4XY, UK \\ ${ }^{3}$ Centers for Disease Control and Prevention, Atlanta, GA 30333, USA
}

\begin{abstract}
Six strains of anaerobic, pleomorphic Gram-positive bacilli, isolated from the human oral cavity and an infected arm wound, were subjected to a comprehensive range of phenotypic and genotypic tests and were found to comprise a homogeneous group. 16S rRNA gene sequence analysis revealed that the isolates were most closely related to Scardovia inopinata CCUG $35729^{\top}$ (94.8-94.9\% 16S rRNA gene sequence similarity). The isolates were saccharolytic and produced acetic and lactic acids as end products of fermentation. The major fatty acids were $\mathrm{C}_{16: 0}(49.8 \%)$ and $\mathrm{C}_{18: 1} \omega 9 \mathrm{c}(35.8 \%)$. Polar lipid analysis revealed a variety of glycolipids, diphosphatidylglycerol, an unidentified phospholipid and an unidentified phosphoglycolipid. No respiratory quinones were detected. The peptidoglycan was of the type A4 $\alpha$ L-Lys-Thr-Glu, with L-lysine partially replaced by L-ornithine. The DNA G +C content of one of the strains, C1A_55 $5^{\top}$, was $55 \mathrm{~mol} \%$. A novel species, Scardovia wiggsiae sp. nov., is proposed to accommodate the six isolates, with the type strain C1A_55 $5^{\top}\left(=\mathrm{DSM} 22547^{\top}=\right.$ CCUG $\left.58090^{\top}\right)$.
\end{abstract}

Phylotype Scardovia C1 was described in a study of the microbiota associated with dentinal caries on the basis of 16S rRNA gene sequence comparisons (Munson et al., 2004). Strains corresponding to this group have subsequently been isolated from both root and occlusal caries (Mantzourani et al., 2009a, b) and oral squamous cell carcinoma tissue (Hooper et al., 2006). Strain C1A_55 ${ }^{\mathrm{T}}$ was isolated from a dentinal caries lesion, strain 04C01 from a root caries lesion and strain 29D03 from a sound, exposed tooth-root surface. Strain T01-04 was isolated from within oral squamous cell carcinoma tissue and strain C04-09 from healthy buccal mucosal tissue. Strain 2008322 was isolated from a wound infection in the arm of an intravenous drug user.

The isolates were cultivated on fastidious anaerobe agar (Lab M) supplemented with $5 \%$ horse blood (FAA) under

The GenBank/EMBL/DDBJ accession numbers of strains C1A_55 ${ }^{\top}$, C04-09, T01-04, 04C01, $29 \mathrm{D03}$ and 2008322 for the 16S rRNA gene sequences are AY278626, G0892823-G0892826 and G0914993 and for the $h s p 60$ sequences are GU301684-GU301686, GU301688, GU301689 and GU301687, respectively.

A supplementary figure and two supplementary tables are available with the online version of this paper. anaerobic conditions $\left(80 \% \mathrm{~N}_{2}, 10 \% \mathrm{H}_{2}, 10 \% \mathrm{CO}_{2}\right)$ at $37{ }^{\circ} \mathrm{C}$. Colony morphologies were recorded after 7 days using a dissecting microscope. Cell morphologies were determined from Gram-stained smears of cells harvested from 2-day-old cultures using $\times 1000$ magnification. Motility was investigated by phase-contrast microscopy with hanging-drop preparations of cultures from peptoneyeast extract-glucose (PYG) broth after $18 \mathrm{~h}$ (Holdeman et al., 1977). Biochemical and physiological tests were performed using standard methods (Jousimies-Somer et al., 2002). The production of acid from sugars was determined in peptone-yeast extract (PY) broth (Holdeman et al., 1977) prepared in an anaerobic workstation with the addition of prereduced anaerobically sterilized sugars. Susceptibility to vancomycin $(5 \mu \mathrm{g})$, kanamycin $(1 \mathrm{mg})$ and colistin $(10 \mu \mathrm{g})$ was determined using special-potency discs (Oxoid) on FAA (Jousimies-Somer et al., 2002). The production of short-chain volatile and non-volatile fatty acids after growth in PYG broth was determined by GC (Holdeman et al., 1977). Enzyme profiles were generated with a Rapid ID 32A anaerobe identification kit (bioMérieux), according to the manufacturer's instructions, using bacteria harvested from Columbia agar plates (Lab M) supplemented with $5 \%$ horse blood after incubation at 
$37{ }^{\circ} \mathrm{C}$ for $72 \mathrm{~h}$. The reference strain Scardovia inopinata CCUG $35729^{\mathrm{T}}$ was obtained from the CCUG.

Analyses of cellular fatty acids, respiratory quinones, polar lipids and peptidoglycan of strains C1A_5 $55^{\mathrm{T}}$ and $S$. inopinata CCUG $35729^{\mathrm{T}}$ were performed simultaneously by Dr Brian Tindall and Dr Peter Schumann at the Identification Service of the DSMZ, Braunschweig, Germany. Fatty acid methyl esters were obtained from $40 \mathrm{mg}$ wet cells scraped from blood agar plates after incubation at $37{ }^{\circ} \mathrm{C}$ for $72 \mathrm{~h}$ by saponification, methylation and extraction using minor modifications of described methods (Kuykendall et al., 1988; Miller, 1982). The fatty acid methyl ester mixtures were separated using the Sherlock Microbial Identification System (MIDI) using an Agilent model $6890 \mathrm{~N}$ GC fitted with a $5 \%$ phenylmethyl silicone capillary column $(0.2 \mathrm{~mm} \times 25 \mathrm{~m})$, a flame-ionization detector, an Agilent model 7683A automatic sampler and a Hewlett Packard computer with the MIDI database. Peaks were automatically integrated and percentages were calculated using the standard software package (MIDI). The GC parameters were as follows: carrier gas, ultrahigh-purity hydrogen; column head pressure, $60 \mathrm{kPa}$; injection volume, $2 \mu \mathrm{l}$; column split ratio, $100: 1$; septum purge, $5 \mathrm{ml} \mathrm{min}^{-1}$; column temperature change, from 170 to $270{ }^{\circ} \mathrm{C}$ at $5{ }^{\circ} \mathrm{C} \mathrm{min}{ }^{-1}$; injection port temperature, $240{ }^{\circ} \mathrm{C}$; and detector temperature, $300{ }^{\circ} \mathrm{C}$.

Respiratory lipoquinones and polar lipids were extracted from $100 \mathrm{mg}$ freeze-dried cells using the two-stage method described by Tindall (1990a, b). Respiratory quinones were extracted using methanol/hexane (Tindall, 1990a, b), followed by phase separation into hexane. Polar lipids were extracted by adjusting the remaining methanol/0.3\% aqueous $\mathrm{NaCl}$ phase (containing the cell debris) to give a chloroform/methanol $/ 0.3 \%$ aqueous $\mathrm{NaCl}$ phase in the ratio $1: 2: 0.8(\mathrm{v} / \mathrm{v})$. The extraction solvent was stirred overnight and the cell debris was pelleted by centrifugation. Polar lipids were recovered into the chloroform phase by adjusting the chloroform/methanol/0.3\% aqueous $\mathrm{NaCl}$ phase to a ratio of $1: 1: 0.9(\mathrm{v} / \mathrm{v})$. Respiratory lipoquinones were separated into different classes by TLC on silica gel (no. 805 023; Macherey-Nagel) using hexane/tert-butyl methyl ether $(9: 1, \mathrm{v} / \mathrm{v})$ as the solvent. UV-absorbing bands corresponding to the different quinone classes were removed from the plate and further analysed by HPLC on a LDC Analytical HPLC (Thermo Separation Products) fitted with a reversed-phase column $(2 \mathrm{~mm} \times 125 \mathrm{~mm} \times$ $3 \mu \mathrm{m}$; model RP18; Macherey-Nagel) using methanol/ heptane $(9: 1, \mathrm{v} / \mathrm{v})$ as the eluent. Respiratory lipoquinones were detected at $269 \mathrm{~nm}$. Polar lipids were separated by two-dimensional TLC on silica gel (no. 818 135; MachereyNagel). The first direction was developed with chloroform/ methanol/water $(65: 25: 4, \mathrm{v} / \mathrm{v})$ and the second direction with chloroform/methanol/acetic acid/water (80:12:15:4, $\mathrm{v} / \mathrm{v})$. Detection was performed using dodecamolybdophosphoric acid for total lipids, Zinzadze reagent for phosphates, ninhydrin for free amino groups, periodate-Schiff for $\alpha$-glycols, Dragendorff for quaternary nitrogen and $\alpha$ naphthol sulphuric acid for glycolipids. Full details are given in Tindall et al. (2007).

Peptidoglycan structure was determined as described elsewhere (Schleifer, 1985; Schleifer \& Kandler, 1972) with the modification that TLC was performed using cellulose instead of paper. Quantitative analysis of amino acids was performed after derivatization by GC and GC/MS as described by MacKenzie (1987).

The DNA G $+\mathrm{C}$ content of the isolates was determined by HPLC as previously described (Wade et al., 1999) using the reference strain Escherichia coli ATCC $11775^{\mathrm{T}}$ for calibration. 16S rRNA gene sequences were determined by sequencing PCR products generated with universal primers as described previously (Downes et al., 2005). Partial hsp60 sequences were obtained from PCR products amplified using the degenerate primers H60F and H60R described by Jian et al. (2001). Sequences were assembled and aligned using the BioEdit program (Hall, 2004). Phylogenetic trees were constructed using MEGA version 4 (Tamura et al., 2007) with the neighbour-joining method from distance matrices prepared with the Jukes-Cantor correction and with the maximum-parsimony method. Thermal renaturation (Huß et al., 1983) was used in duplicate to estimate the DNA-DNA relatedness between strain C1A_55 ${ }^{\mathrm{T}}$ and the other five isolates.

The results of the phenotypic tests are summarized in the species description. The six isolates were anaerobic, nonmotile, non-spore-forming Gram-positive bacilli, 0.6$0.7 \mu \mathrm{m}$ wide and 1.6-4 $\mu \mathrm{m}$ long. Cells were pleomorphic with straight, slightly curved and some club-shaped forms arranged singularly, in pairs or in short chains, with some branched and diphtheroidal arrangements. After 7 days on FAA, colonies were pleomorphic with strain variation in colony morphology. Colonies ranged from 0.4 to $1.2 \mathrm{~mm}$ in diameter and were circular, irregular or molar tooth in shape, entire or undulate, grey, off-white or cream, convex and opaque. On further incubation, isolated colonies became more convoluted and irregular and denser areas of growth became more yellow-orange and developed a waxy, wrinkled surface. There was no detectable growth on FAA in air supplemented with $5 \% \mathrm{CO}_{2}$. The isolates were sensitive to the special potency discs containing vancomycin and kanamycin but were resistant to colistin. There was moderate growth of all isolates in PY broth $(2-3+$ on a scale of $0-4+$ ) while growth was enhanced by the addition of $1 \%$ fermentable carbohydrates $(3-4+)$. The isolates were saccharolytic with variable fermentation of lactose, melibiose and salicin: two of the six isolates were positive for lactose fermentation while four isolates were positive for melibiose and salicin fermentation. Other fermentation reactions are listed in the species description and the reactions that distinguish the novel strains from $S$. inopinata are shown in Table 1. Hydrolysis of aesculin was variable: four isolates were positive and two isolates were negative. The end products of fermentation in PYG 
Table 1. Characteristics that differentiate the novel strains from Scardovia inopinata

Data were taken from this study and Crociani et al. (1996).

\begin{tabular}{|lcc|}
\hline Characteristic & $\begin{array}{c}S . \text { wiggsiae sp. nov. } \\
(n=6)\end{array}$ & $\begin{array}{c}\text { S. inopinata } \\
(n=32)\end{array}$ \\
\hline Fermentation of: & & - \\
D-Arabinose & + & + \\
Dextran & - & - \\
Galactose & + & + \\
Xylose & - & \\
\hline
\end{tabular}

broth were major amounts of acetic acid and minor-tomoderate amounts of lactic acid. The molar ratio of acetic acid/lactic acid was $1.9: 1$.

All six isolates gave positive reactions with Rapid ID 32A for $\alpha$-galactosidase, $\alpha$-glucosidase, raffinose fermentation, arginine arylamidase, proline arylamidase, phenylalanine arylamidase, leucine arylamidase, tyrosine arylamidase, histidine arylamidase and serine arylamidase and gave a weakly positive reaction for glycine arylamidase. There was variation in the reactions for $\beta$-galactosidase and $\beta$ glucosidase. The remaining tests were negative, resulting in a Rapid ID 32A profile of $4{ }^{4} / 5 \% 1033505$.

Almost-complete 16S rRNA gene sequences were obtained for all six isolates. In pairwise comparisons, the isolates shared at least $99.7 \%$ 16S rRNA gene sequence similarity over 1460 unambiguously aligned bases. Mean DNA-DNA relatedness (duplicate measurements) between strain C1A_55 ${ }^{\mathrm{T}}$ and strains 04C01, 29D03, T01-04, C04-09 and 2008322 were $82(79,85), 87(83,90), 85(78,92), 84(79,89)$ and $96 \%(93 \%, 99 \%)$, respectively, which confirmed that the strains belonged to the same taxon at the species level.

Phylogenetic analysis of the 16S rRNA gene sequences with the neighbour-joining method revealed the isolates to be most closely related to $S$. inopinata DSM $10107^{\mathrm{T}}$, with which the isolates shared 94.8-94.9\% 16S rRNA gene sequence similarity (Fig. 1). The maximum-parsimony method gave essentially the same tree, but Parascardovia denticolens DSM $10105^{\mathrm{T}}$ was placed outside the branch including Alloscardovia omnicolens CCUG $31649^{\mathrm{T}}$ and Metascardovia criceti $\mathrm{OMB}_{105^{\mathrm{T}}}$. Comparison of $h s p 60$ sequences yielded a tree with similar topology to that obtained with 16S rRNA gene sequences except that Gardnerella vaginalis ATCC $14018^{\mathrm{T}}$, which was embedded within the genus Bifidobacterium in the $16 \mathrm{~S}$ rRNA gene sequence tree, was found to be related to A. omnicolens CCUG $31649^{\mathrm{T}}$ (Fig. 2). The DNA G $+\mathrm{C}$ content of strains C1A_55 ${ }^{\mathrm{T}}$ and C04-09 was $55 \mathrm{~mol} \%$. The DNA G+C content of S. inopinata CCUG $35729^{\mathrm{T}}$ was previously reported to be $45 \mathrm{~mol} \%$ (Crociani et al., 1996). As a $10 \%$ disparity in $\mathrm{G}+\mathrm{C}$ content between strains that share approximately $95 \% 16 \mathrm{~S}$ rRNA gene sequence similarity is unusual, the DNA G+C content of S. inopinata CCUG $35729^{\mathrm{T}}$ was determined in this study and was found to be $54 \mathrm{~mol} \%$.

The major fatty acids identified in strain C1A $555^{\mathrm{T}}$ were $\mathrm{C}_{16: 0}$ and $\mathrm{C}_{18: 1} \omega 9 c$ (Supplementary Table S1, available in IJSEM Online). S. inopinata CCUG $35729^{\mathrm{T}}$ showed a similar profile but $\mathrm{C}_{14: 0}$ was also a major component in this strain. Polar lipid analysis revealed a variety of glycolipids together with diphosphatidylglycerol, an unidentified phospholipid and an unidentified phosphoglycolipid in strain C1A_55 $5^{\mathrm{T}}$ and $S$. inopinata CCUG $35729^{\mathrm{T}}$, although the distribution of glycolipids in particular differed between the two strains (see Supplementary Fig. S1). Respiratory quinones were not detected. The peptidoglycan of strain C1A_5 $55^{\mathrm{T}}$ was found to be of the type A $4 \alpha$ L-Lys-Thr-Glu, with L-lysine partially replaced by L-ornithine, while that of $S$. inopinata CCUG $35729^{\mathrm{T}}$ was of the type A4 $\alpha$ L-Lys-Ser-Glu, with L-lysine and serine partially replaced by L-ornithine and threonine, respectively.

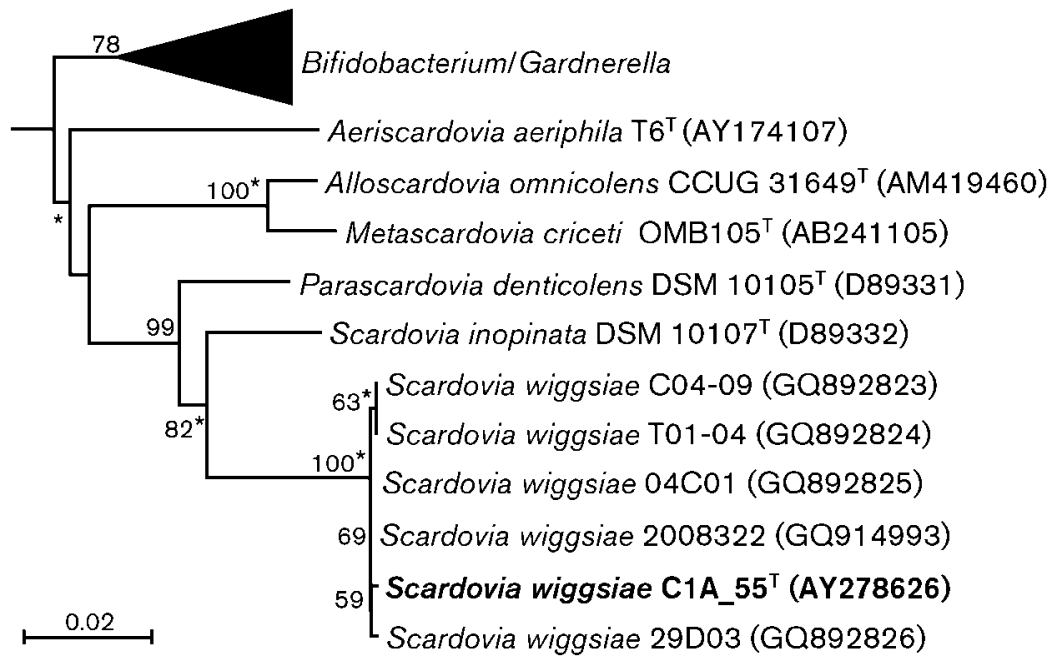

Fig. 1. Neighbour-joining phylogenetic tree based on 16S rRNA gene sequence comparisons over 1301 aligned bases showing the relationships between Scardovia wiggsiae sp. nov. and representatives of related species. The taxa included in the Bifidobacterium/ Gardnerella group are listed in Supplementary Table S2 (see IJSEM Online). Bootstrap values $(>50 \%)$ based on 500 replications are shown at branch nodes. Asterisks indicate that the corresponding nodes were also recovered in trees constructed with the maximum-parsimony method. Bar, 0.02 substitutions per nucleotide site. 


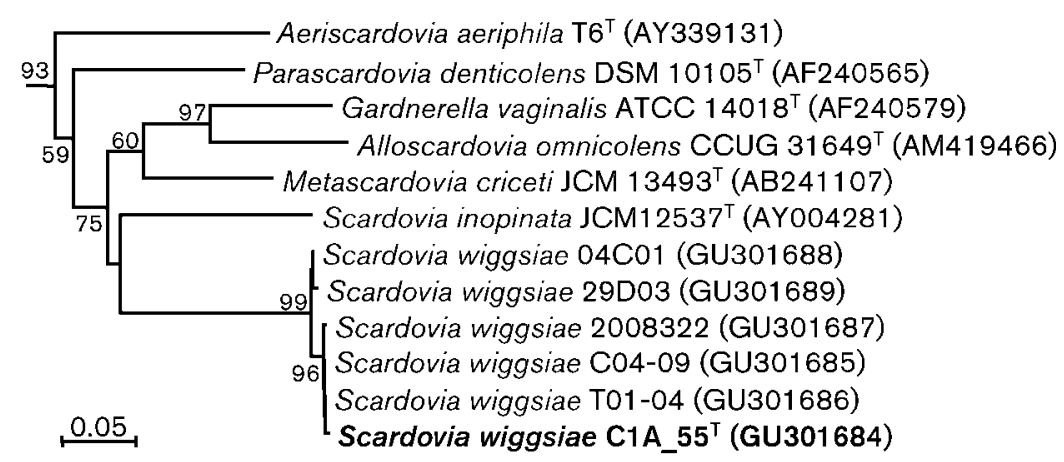

Fig. 2. Neighbour-joining phylogenetic tree based on $h s p 60$ sequence comparisons over 452 aligned bases showing the relationships between Scardovia wiggsiae sp. nov. and representatives of related species. Bootstrap values $(>50 \%)$ based on 500 replications are shown at branch nodes. Bar, 0.05 substitutions per nucleotide site.
The six isolates studied here constitute a homogeneous group and are clearly distinct from any species with validly published names. We therefore propose a novel species, with the name Scardovia wiggsiae sp. nov., to accommodate these isolates.

\section{Emended description of the genus Scardovia Jian and Dong 2002}

The description is as given by Crociani et al. (1996) and Jian \& Dong (2002) with the following additions. Dextran fermentation is variable and cell morphology ranges from small coccoid cells to a mixture of longer and straight, curved and branched cells in diphtheroidal arrangements. The major fatty acids are $\mathrm{C}_{16: 0}$ and $\mathrm{C}_{18: 1} \omega 9 \mathrm{c}$. Polar lipids consist of a variety of glycolipids together with diphosphatidylglycerol, an unidentified phospholipid and an unidentified phosphoglycolipid. No respiratory quinones are present. The DNA G $+\mathrm{C}$ content is $54-55 \mathrm{~mol} \%$.

\section{Description of Scardovia wiggsiae sp. nov.}

Scardovia wiggsiae (wiggs'i.ae. N.L. fem. gen. n. wiggsiae of Wiggs, named in honour of Lois Wiggs, American microbiologist, for her contributions to anaerobic microbiology).

The description is based on five strains isolated from the human oral cavity and one strain isolated from an infected arm wound. Gram-positive, anaerobic, non-spore-forming and non-motile bacilli $(0.6-0.7 \mu \mathrm{m} \times 1.6-4 \mu \mathrm{m})$. Cells are pleomorphic with straight, slightly curved and some clubshaped forms arranged singularly, in pairs or in short chains, with some branched and diphtheroidal arrangements. After 7 days on FAA, colonies are pleomorphic, $0.4-1.2 \mathrm{~mm}$ in diameter, circular, irregular or molar tooth in shape, entire or undulate, grey, off-white or cream, convex and opaque. Growth in broth produces a moderate turbidity that is enhanced by the addition of fermentable carbohydrates. Saccharolytic. Ferments D-arabinose, fructose, galactose, glucose, maltose, raffinose, ribose and sucrose without production of gas; weakly ferments mannose; does not ferment cellobiose, dextran, mannitol, melezitose, rhamnose, sorbitol, trehalose or xylose. Fermentation of lactose, melibiose and salicin is variable.
Major amounts of acetic acid and minor-to-moderate amounts of lactic acid are produced in peptone-yeast extract-glucose broth. Aesculin hydrolysis is variable; Larginine, gelatin and urea are not hydrolysed. Indole, catalase and $\mathrm{H}_{2} \mathrm{~S}$ are not produced. Nitrate is not reduced. The Rapid ID 32A profile is $4{ }_{5}^{4}{ }_{5}^{0} / 14033505$. The major fatty acids are $\mathrm{C}_{16: 0}$ and $\mathrm{C}_{18: 1} \omega 9 \mathrm{c}$. Cellular polar lipids include a variety of glycolipids together with diphosphatidylglycerol, an unidentified phospholipid and an unidentified phosphoglycolipid. No respiratory quinones are detectable. The peptidoglycan is of the type A $4 \alpha$ L-LysThr-Glu, with L-lysine partially replaced by L-ornithine.

The type strain is C1A_5 ${ }^{\mathrm{T}}\left(=\mathrm{DSM} \quad 22547^{\mathrm{T}}=\mathrm{CCUG}\right.$ $58090^{\mathrm{T}}$ ), isolated from the human oral cavity and an arm wound of an intravenous drug user. The DNA G+C content of the type strain is $55 \mathrm{~mol} \%$. The species is Human Oral Taxon 195 in the Human Oral Microbiome Database (http://www.homd.org).

\section{Emended description of Scardovia inopinata (Crociani et al. 1996) Jian and Dong 2002}

The description is as given by Crociani et al. (1996) and Jian \& Dong (2002) with the following additions. The major fatty acids are $\mathrm{C}_{16: 0}, \mathrm{C}_{18: 1} \omega 9 \mathrm{c}$ and $\mathrm{C}_{14: 0}$. The cellular polar lipids include a variety of glycolipids together with diphosphatidylglycerol, an unidentified phospholipid and an unidentified phosphoglycolipid. No respiratory quinones are detectable. The peptidoglycan is of the type A $4 \alpha$ L-Lys-Ser-Glu, with L-lysine and serine partially replaced by L-ornithine and threonine, respectively. The DNA $\mathrm{G}+\mathrm{C}$ content of the type strain is $54 \mathrm{~mol} \%$.

\section{Acknowledgements}

This research was supported by Guy's \& St Thomas' Charity (grant no. R050724). The authors acknowledge financial support from the UK Department of Health via the UK National Institute for Health Research (NIHR) comprehensive Biomedical Research Centre award to Guy's \& St Thomas' NHS Foundation Trust in partnership with King's College London. The findings and conclusions in this report are those of the authors and do not necessarily represent the official position of the Centers for Disease Control and Prevention. Strain 2008322 was the kind gift of Dr Julie Ribes of the University of Kentucky, UKHealthCare Chandler Hospital, Lexington, KY, USA. 


\section{References}

Crociani, F., Biavati, B., Alessandrini, A., Chiarini, C. \& Scardovi, V. (1996). Bifidobacterium inopinatum sp. nov. and Bifidobacterium denticolens sp. nov., two new species isolated from human dental caries. Int J Syst Bacteriol 46, 564-571.

Downes, J., Sutcliffe, I., Tanner, A. C. \& Wade, W. G. (2005). Prevotella marshii sp. nov. and Prevotella baroniae sp. nov., isolated from the human oral cavity. Int J Syst Evol Microbiol 55, 1551-1555.

Hall, T. (2004). BioEdit. Biological sequence alignment editor for Win95/98/NT/2K/XP. Carlsbad, CA: Ibis Biosciences.

Holdeman, L. V. H., Cato, E. P. \& Moore, W. E. C. (1977). Anaerobe Laboratory Manual, 4th edn. Blacksburg, VA: Virginia Polytechnic Institute and State University.

Hooper, S. J., Crean, S. J., Lewis, M. A., Spratt, D. A., Wade, W. G. \& Wilson, M. J. (2006). Viable bacteria present within oral squamous cell carcinoma tissue. J Clin Microbiol 44, 1719-1725.

Huß, V. A. R., Festl, H. \& Schleifer, K. H. (1983). Studies on the spectrophotometric determination of DNA hybridization from renaturation rates. Syst Appl Microbiol 4, 184-192.

Jian, W. \& Dong, X. (2002). Transfer of Bifidobacterium inopinatum and Bifidobacterium denticolens to Scardovia inopinata gen. nov., comb. nov., and Parascardovia denticolens gen. nov., comb. nov., respectively. Int J Syst Evol Microbiol 52, 809-812.

Jian, W., Zhu, L. \& Dong, X. (2001). New approach to phylogenetic analysis of the genus Bifidobacterium based on partial HSP60 gene sequences. Int J Syst Evol Microbiol 51, 1633-1638.

Jousimies-Somer, H., Summanen, P., Citron, D. M., Baron, E. J., Wexler, H. M. \& Finegold, S. M. (2002). Wadsworth Anaerobic Bacteriology Manual, 6th edn. Belmont, CA: Star Publishing.

Kuykendall, L. D., Roy, M. A., O’Neill, J. J. \& Devine, T. E. (1988). Fatty acids, antibiotic resistance, and deoxyribonucleic acid homology groups of Bradorhizobium japonicum. Int J Syst Bacteriol 38, 358361.

MacKenzie, S. L. (1987). Gas chromatographic analysis of amino acids as the $N$-heptafluorobutyryl isobutyl esters. J Assoc Off Anal Chem 70, 151-160.
Mantzourani, M., Fenlon, M. \& Beighton, D. (2009a). Association between Bifidobacteriaceae and the clinical severity of root caries lesions. Oral Microbiol Immunol 24, 32-37.

Mantzourani, M., Gilbert, S. C., Sulong, H. N., Sheehy, E. C., Tank, S., Fenlon, M. \& Beighton, D. (2009b). The isolation of bifidobacteria from occlusal carious lesions in children and adults. Caries Res 43, 308-313.

Miller, L. T. (1982). Single derivatization method for routine analysis of bacterial whole-cell fatty acid methyl esters, including hydroxy acids. J Clin Microbiol 16, 584-586.

Munson, M. A., Banerjee, A., Watson, T. F. \& Wade, W. G. (2004). Molecular analysis of the microflora associated with dental caries. J Clin Microbiol 42, 3023-3029.

Schleifer, K. H. (1985). Analysis of the chemical composition and primary structure of murein. Methods Microbiol 18, 123-156.

Schleifer, K. H. \& Kandler, O. (1972). Peptidoglycan types of bacterial cell walls and their taxonomic implications. Bacteriol Rev 36, 407-477.

Tamura, K., Dudley, J., Nei, M. \& Kumar, S. (2007). MEGA4: Molecular evolutionary genetics analysis (MEGA) software version 4.0. Mol Biol Evol 24, 1596-1599.

Tindall, B. J. (1990a). A comparative study of the lipid composition of Halobacterium saccharovorum from various sources. Syst Appl Microbiol 13, 128-130.

Tindall, B. J. (1990b). Lipid composition of Halobacterium lacusprofundi. FEMS Microbiol Lett 66, 199-202.

Tindall, B. J., Sikorski, J., Smibert, R. M. \& Krieg, N. R. (2007). Phenotypic characterization and the principles of comparative systematics. In Methods for General and Molecular Microbiology, 3rd edn, pp. 330-393. Edited by C. A. Reddy, T. J. Beveridge, J. A. Breznak, G. Marzluf, T. M. Schmidt \& L. R. Snyder. Washington, DC: American Society for Microbiology.

Wade, W. G., Downes, J., Dymock, D., Hiom, S. J., Weightman, A. J., Dewhirst, F. E., Paster, B. J., Tzellas, N. \& Coleman, B. (1999). The family Coriobacteriaceae: reclassification of Eubacterium exiguum (Poco et al. 1996) and Peptostreptococcus heliotrinreducens (Lanigan 1976) as Slackia exigua gen. nov., comb. nov. and Slackia heliotrinireducens gen. nov., comb. nov., and Eubacterium lentum (Prevot 1938) as Eggerthella lenta gen. nov., comb. nov. Int J Syst Bacteriol 49, 595-600. 